\title{
La adopción abierta
}

\section{María Angustias Martos Calabrús}

Universidad de Almería, La Coruña, España mamartos@ual.es

La Ley 26/2015, de 28 de julio, de Protección a la Infancia y a la Adolescencia, ha introducido una nueva excepción en los efectos jurídicos esenciales de la adopción: la extinción de los vínculos jurídicos entre el adoptado y la familia de origen, otorgando la posibilidad de que pueda mantener, con algún miembro de la familia de origen, alguna forma de relación o contacto a través de visitas o de comunicaciones, lo que se ha denominado, por el legislador, "adopción abierta". En el Preámbulo de la Ley se justifica esta excepción en "la búsqueda de alternativas consensuadas, familiares y permanentes que permitan dotar de estabilidad familiar a algunos menores, especialmente los más mayores, cuya adopción presenta más dificultades".

La adopción se configura en la actualidad, en España, como un instrumento de integración familiar que se constituye por resolución judicial, que confiere al adoptado un nuevo estado civil y extingue todo vínculo jurídico con la familia de origen salvo en los casos recogidos en el artículo 178 del Código civil: la adopción de hijo de cónyuges o pareja estable, la adopción de menor que tiene determinada sólo una filiación y como, novedad, la adopción en que se acuerde el mantenimiento de las relaciones jurídicas entre el menor y su familia de origen.

La ruptura del vínculo jurídico con la familia de origen o biológica, no ha sido siempre un efecto de esta institución. En Roma ${ }^{1}$ el adoptado podía mantener vínculos jurídicos con la familia de origen, pues, de las dos clases de adopción -la plena y la menos plena- la menos plena no confería nuevo estado civil y el menor mantenía los vínculos jurídicos con la familia de origen.

\footnotetext{
1 En la época de Justiniano: la adopción plena se realizaba por un ascendiente, se transfería la patria potestad y confería al adoptado el derecho a la sucesión del adoptante. La adopción menos plena estaba concebida para personas ajenas a la familia, el adoptante no adquiría la patria potestad del adoptado ni éste derecho sucesorio sobre aquellos (Guzmán Peces, M. «Las distintas funciones y líneas de evolución». La adopción internacional. Guía de adoptantes, mediadores y juristas. La Ley, 2007, pág. 41)
} 
En la redacción originaria del Código civil, la adopción se configura, sin distinción de clases, con la finalidad de satisfacer a los matrimonios sin hijos, el deseo de un heredero; mantiene los vínculos jurídicos con la familia de origen: el adoptado, decía el artículo 175, podrá usar, con el apellido de su familia, el del adoptante, expresándolo así en la escritura de adopción, y el artículo 176 añadía que el adoptado tampoco adquiere derecho a heredar, fuera de testamento, al adoptante, a menos que en la escritura de adopción se haya éste obligado a instituirle heredero.

Igualmente, con la reforma sufrida por esta institución por la Ley 24 de abril de 1958, con la que se introducen dos clases de adopción, la «plena» y «menos plena» - que se llamaría posteriormente «simple» con la reforma de la Ley 7/1970, de 4 de julio-, los vínculos jurídicos se mantiene en la menos plena. Con la adopción plena, que se constituía para menores de catorce años abandonados, el adoptado se integraba en la familia adoptiva, se le otorgaban los apellidos del adoptante y tenía derecho sucesorio y, por tanto, se extinguían todo vínculo jurídico con la familia de origen. Con la adopción menos plena o simple, que se constituía para los menores cuya familia natural o biología se conocía, es decir huérfanos por su familia extensa, y para menores huérfanos en general, que se realizaba con fines hereditarios, y por ello se les reconocían derechos en la sucesión intestada del adoptante seguían conservando los apellidos de la familia de origen, es decir, que mantenían el vínculo jurídico (art. 180 del Cc: En la escritura de adopción podrá convenirse la sustitución de los apellidos del adoptando por los del adoptante o adoptantes, o el uso de un apellido de cada procedencia, en cuyo caso se fijará el orden de los mismos. A falta de pacto expreso, el adoptado conservará sus propios apellidos).

No es hasta la Ley 21/1987, de 11 de noviembre, cuando se reforma en profundidad la institución de la adopción, suprimiéndose las clases de adopción y consagrándola como instrumento que integra plenamente al adoptado en la familia del adoptante y donde, como efecto general, se produce (art. $178.1 \mathrm{Cc}$ ) la extinción de los vínculos jurídicos entre el adoptado y su familia de origen².

2 Como indica Pérez Álvarez "la evolución de la adopción se caracteriza por la paulatina reconducción de la institución, desde un régimen jurídico pensado inicialmente para satisfacer los deseos de paternidad de quienes no tienen hijos, hasta otro que tiene al adoptado como referente primordial -primacía del interés del 
Con la nueva reforma introducida por la Ley 26/2015, de 28 de julio, y como evolución del sistema de protección de menores llevado a cabo en estas dos décadas en España, el legislador ha entendido que es el momento de introducir la adopción abierta, atendiendo al interés del menor, es decir, que cuando las condiciones sean favorables, puede ser beneficioso para algunos menores mantener la relación con la familia de origen, mediante el derecho de comunicación o de visitas, ya que estas medidas se adoptan como derechos del menor en el ámbito de la protección de menores (acogimientos o guardas), salvo en los casos de privación de la patria potestad. Así la ley reconoce la posibilidad de constituir una adopción en la que se mantenga relación jurídica con la familia de origen atendiendo al interés del menor, a su situación familiar, edad o cualquier otra circunstancia significativa valorada por la Entidad Pública, a través de visitas o comunicaciones entre el menor adoptado y los miembros de la familia de origen que se considere, favoreciéndose especialmente, cuando sea posible, la relación entre los hermanos biológicos (art. 178.4 CC). Con esta institución se permite que pueda mantenerse contacto no sólo entre la familia de origen y el adoptado, sino entre los miembros de la familia de origen y la adoptiva, en una búsqueda de alternativas consensuadas con el fin de que no quiebren definitivamente los lazos con la familia de procedencia del adoptado ${ }^{3}$.

La adopción abierta, no se regula como una clase nueva de adopción, sino que es la misma institución, en la que se exigen los mismos requisitos para constituirla y el mismo procedimiento, y que tiene el mismo efecto en cuanto extingue el vínculo jurídico (art. 178. 1. CC) pero con mantenimiento de relaciones jurídicas con la familia de origen en los términos que aparezcan en la resolución judicial que la constituya (derecho de visitas y de comunicación).

Con la adopción se constituye una relación jurídica de filiación entre el adoptado y el adoptante (art. 108.1 CC) idéntica a la filiación por naturaleza

menor-, y que conlleva la atribución de la patria potestad a los adoptantes más idóneos".( PEREZ ALVAREZ "Comentario al artículo 175", en CAÑIZARES LASO A., DE PABLO CONTRERAS P., ORDUÑA MORENO F.J., VALPUESTA FERNÁNDEZ R., Código Civil comentado, Aranzadi, $2^{\circ}$ ed.) (URL 178 aranz codigos_167404565)

3 Vid. RUIZ-RICO RUIZ-MORÓN, J. (2016). «Últimas reformas de las instituciones privadas de protección de menores y la filiación por la Ley 26/2015, de modificación del sistema de protección a la infancia y la adolescencia». Revista Doctrinal Aranzadi Civil-Mercantil , núm. 3, pág. 10 
(art. 108.2 $2^{4}$, se determinan los apellidos de los menores adoptados art. 109), se atribuye a los adoptantes la patria potestad sobre el adoptado (art. 154), el adoptado adquiere la nacionalidad y la vecindad civil del adoptante (art. 19 y 14 ) y pierde la de su familia de origen, se origina una relación de parentesco entre adoptado y adoptantes y la familia de estos (art, 915 y ss) y, como consecuencia, hace exigible la obligación de alimentos entre parientes (art. 142), y quedan determinados los derechos sucesorios de la familia adoptante (art. 807 y ss y 930 y ss), extinguiéndose todos estos vínculos jurídicos con respectos a la familia de origen $^{5}$.

Pero el Código civil, en el artículo 178, recoge unas excepciones en los que estos vínculos jurídicos no se extinguen, entre ellos la adopción abierta. El párrafo segundo del artículo enumera, dos supuestos: a) cuando el adoptado sea hijo del cónyuge o de la persona unida al adoptante por análoga relación de afectividad a la conyugal, aunque el consorte o la pareja hubiera fallecido y b) cuando sólo uno de los progenitores haya sido legalmente determinado, siempre que tal efecto hubiera sido solicitado por el adoptante, el adoptado mayor de doce años y el progenitor cuyo vínculo haya de persistir. En tales excepciones el legislador no elimina los vínculos con una de las ramas familiares anteriores del adoptado, bien por no existir incompatibilidad, bien, incluso, porque, de lo contrario, iría en contra de la lógica natural, ya que, en los dos casos, la filiación natural se mantiene con uno de los progenitores: el menor tendrá una filiación natural, la que se mantiene, con uno y otra adoptiva, la que se constituye, con el otro. ${ }^{6}$

Sin embargo, la adopción abierta no podemos entenderla como una excepción similar a las de los párrafos anteriores, ya que, constituida, extingue

4 Este principio de equiparación de filiaciones se recoge en el segundo párrafo del art. 108: "la filiación matrimonial y la no matrimonial, así como la adoptiva, surten los mismos efectos, conforme a las disposiciones de este Código"

5 Todos estos efectos hace afirma a la doctrina, que la adopción, no confiere al adoptado un status filii, sino una verdadero status familiae, y como consecuencia del mismo se produce la ruptura de los vínculos jurídicos con la familia anterior. Vid MAYOR DEL HOYO, M. V., «Comentario del art. 178 », en Código Civil comentado, op. cit. (URL 178 aranz_codigos_167404565)

$6 \mathrm{Al}$ pasar de una única relación paterno-filial a una doble relación paterno-filial, será necesario a la adaptación jurídica del adoptado, en materias como apellidos, vecindad civil, nacionalidad... debiéndose aplicar las normas específicas que regulan tales materias (arts. 109 Cc, $14.3 \mathrm{Cc}, 19 \mathrm{Cc} . .$. ). 
las relaciones de filiación y de parentesco, la patria potestad, los apellidos, los derechos de alimentos, los derechos sucesorios con su familia de origen -igual que en la adopción tradicional-. Lo único que se mantiene es alguna forma de relaciones o contacto con la familia de origen o con algún miembro de ella $\mathrm{y}$, en todo caso, cuando existan hermanos. Ahora bien, lo que tiene carácter excepcional es adoptar estas medidas, ya que sólo se podrán acordar atendiendo al interés del menor, a la vista de su situación familiar, edad y cualquier otra circunstancia; siendo el juez en la resolución judicial que constituya la adopción, quien acordará la forma de llevar a cabo la relación entre el menor y la familia de origen, que podrá ir desde un régimen de visitas a un mero contacto telefónico o un cruce de cartas, debiendo fijar la periodicidad, duración y condiciones y si fuera necesario que esta relación se lleva a cabo con la intermediación de la Entidad Pública o entidades acreditadas a tal fin (art. 178.4.3 Cc). En definitiva, acordará cualquier medida que considere adecuada al interés del menor?

En la misma resolución, el juez tendrá que determinar el seguimiento de las medidas acordadas que según el artículo 178.4.2, realizará por la Entidad Pública de forma obligatoria, en todo caso, consistente en la remisión al Juez de informes periódicos sobre el desarrollo de las visitas y comunicaciones, al menos durante los dos primeros años. Pasados los dos años ya no serán obligatorios los informes, aunque el juez podrá seguir solicitándolos.

Por ultimo durante la validez de la medida, la Entidad Pública, el menor, si tuviese suficiente madurez y, en todo caso, si fuera mayor de doce años, los padres adoptivos y la familia de origen (art. 178.4.3 Cc), podrán solicitar, en interés del menor, el mantenimiento o modificación del régimen de visitas y comunicaciones con la familia de origen e, incluso, su suspensión o finalización ( art. 178.4.2 in fine Cc).

7 Por tanto si el menor ya tenía constituido un derecho de visitas o de comunicación con anterioridad, por resolución administrativa que acordara su acogimiento o guarda, el juez podrá mantener o modificar atendiendo a las circunstancias e interés del menor y del miembro de la familiar de origen y de la familia adoptante. 
